\title{
frontiers
}

FOR YOUNG MINDS

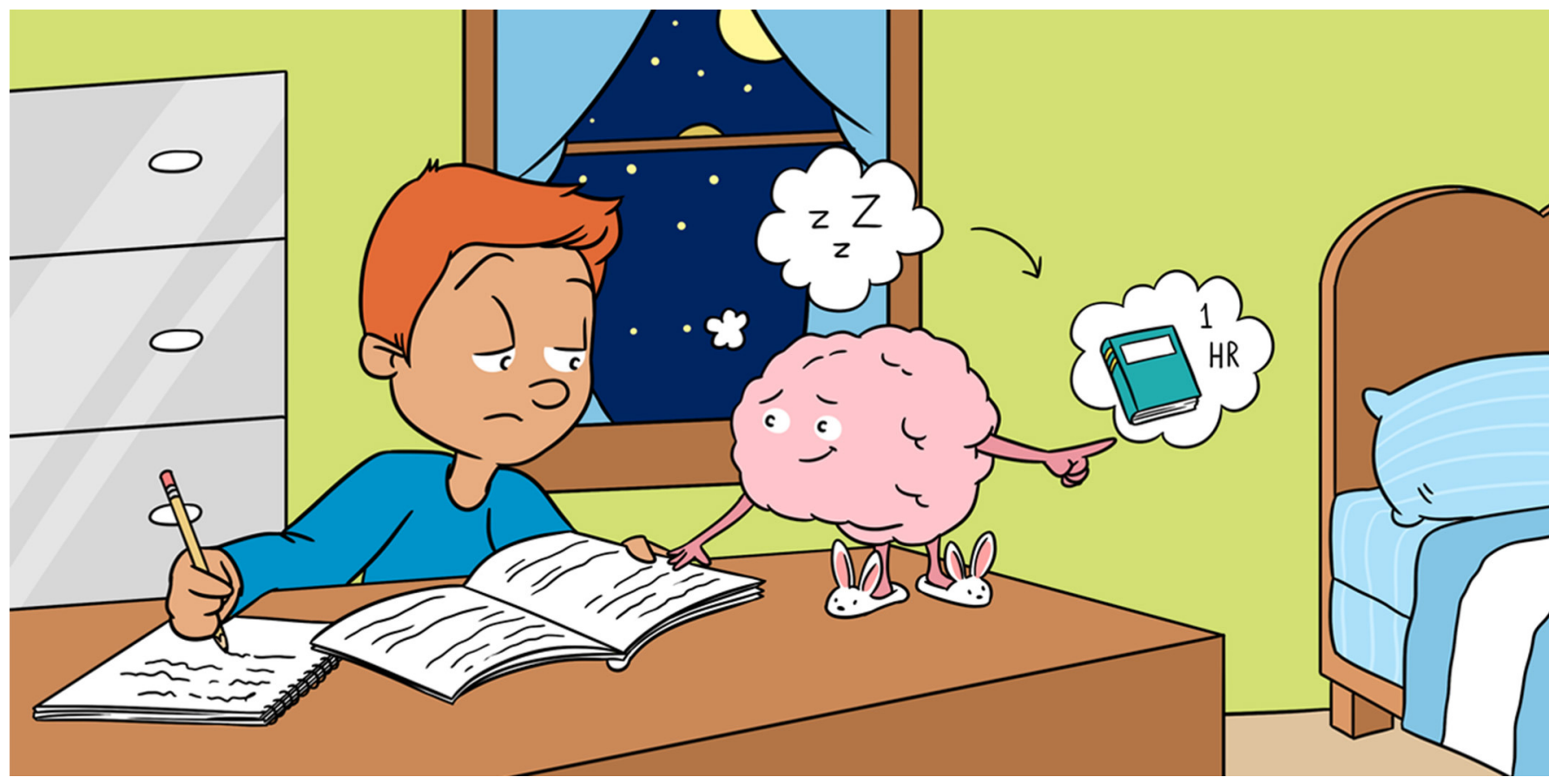

\section{UNDERSTANDING YOUR BRAIN TO HELP YOU LEARN BETTER}

Jérémie Blanchette Sarrasin ${ }^{1,2^{*}}$, Lorie-Marlène Brault Foisy ${ }^{1,2}$, Geneviève Allaire-Duquette $^{3}$ and Steve Masson ${ }^{1,2}$

${ }^{1}$ Département de Didactique, Université du Québec à Montréal, Montréal, QC, Canada

${ }^{2}$ Laboratory for Research in Neuroeducation, Montréal, QC, Canada

${ }^{3}$ Department of Mathematics, Science and Technology Education, The Constantiner School of Education, Tel Aviv University, Tel Aviv, Israel

YOUNG REVIEWERS:

DR. H.

BAVINCK

SCHOOL

AGES: 8-12

LOCARNO

HIGH

SCHOOL

AGES: $17-18$
The past few years have been marked by a large number of discoveries about the learning brain. Those insights have the potential to support teachers in designing even better classroom environments to help you learn better. While understanding the brain can be helpful for teachers, this knowledge can also be beneficial for you as a student. For instance, it can encourage you to believe in your capacity to improve your own skills. Such beliefs make it more likely for you to make an effort and to make better use of supportive learning strategies [1]. In this article, we briefly present some core principles of the learning brain and suggest learning strategies inspired by neuroscience for you to try at school or at home. 
Figure 1

Figure illustrating two neurons that are connected.

\section{Figure 2}

Figure illustrating the very large number of connections between neurons.

\section{NEUROPLASTICITY}

The ability of your brain to change, that is to create, strenghten, weaken or dismantle connections between your neurons.

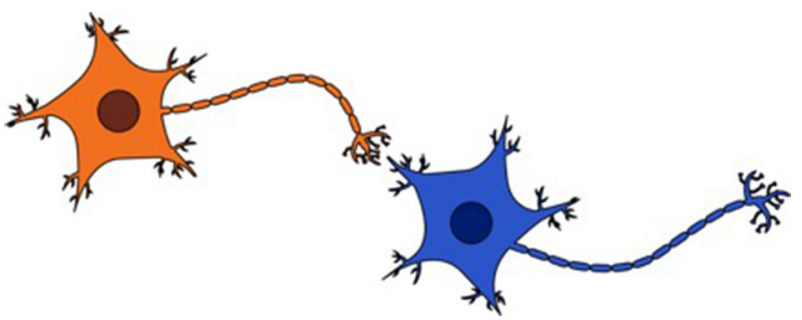

Figure 1

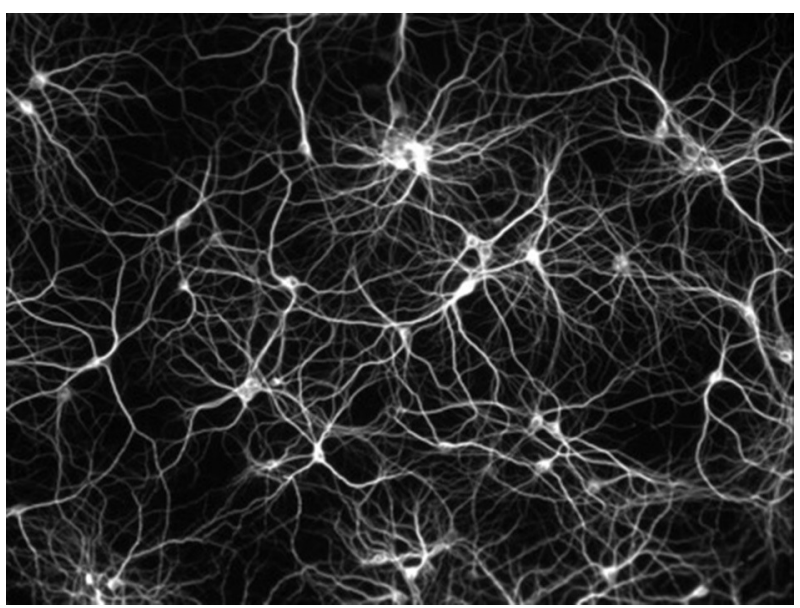

Figure 2

\section{WHAT HAPPENS IN MY BRAIN WHEN I AM LEARNING?}

Your brain is primarily composed of about 85 billion neurons, which is more than the number of stars you can see with the naked eye in the night sky. A neuron is a cell which acts as a messenger, sending information in the form of nerve impulses (like electrical signals) to other neurons (see Figure 1). For example, when you are writing, some neurons in your brain send the "move fingers" message to other neurons and this message then travels through the nerves (like cables) all the way to your fingers. The electrical signals that are communicated from one neuron to another are therefore what allows you to do everything you do: write, think, see, jump, talk, compute, and so on. Each neuron can be connected with up to 10,000 other neurons, leading to a large number of connections in your brain [2], which looks like a very dense spider web (see Figure 2).

When you are learning, important changes take place in your brain, including the creation of new connections between your neurons. This phenomenon is called neuroplasticity. The more you practice, the stronger these connections become. As your connections strengthen, the messages (nerve impulses) are transmitted increasingly faster, making them more efficient [3]. That is how you become better at anything you learn whether it is playing football, reading, drawing, etc. We can compare the connections between your neurons to trails in a 
Figure 3

Figure illustrating the analogy of the trail in the forest.

\section{REPEATEDLY}

ACTIVATING YOUR NEURONS

Practicing a lot, trying to retrieve information from your memory, for example by explaining a concept to a friend or answering quiz questions.

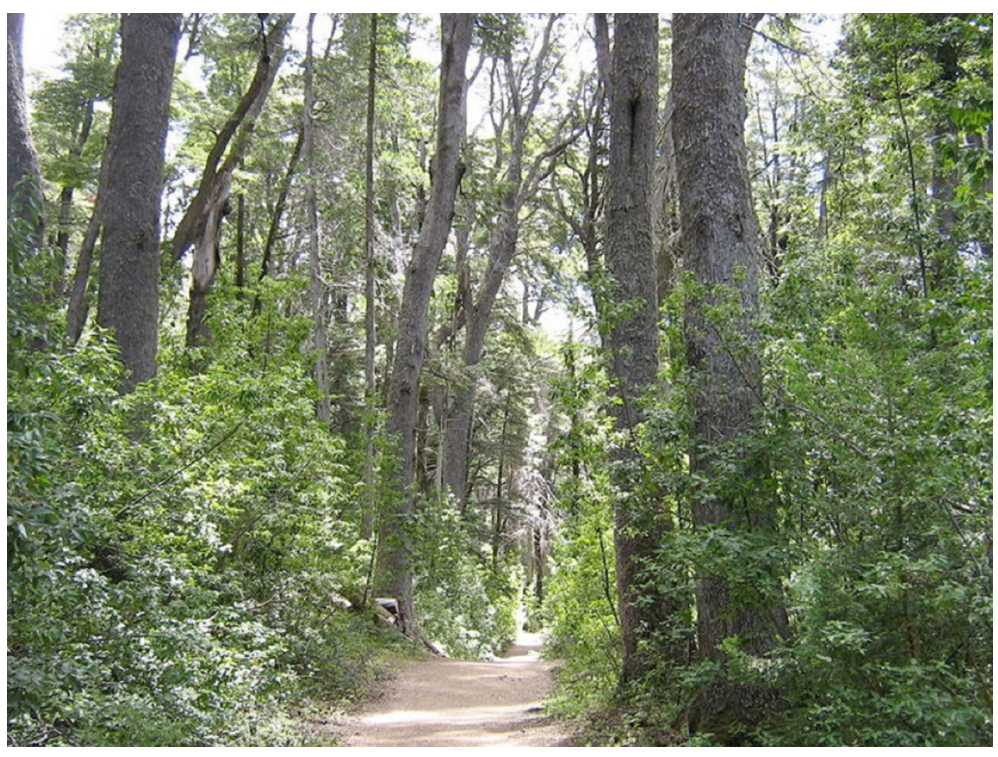

Figure 3

forest (see Figure 3). Walking through a forest without a trail is difficult, because you have to compact and push the vegetation and branches out of the way to carve your way through. But the more you use the same trail, the easier and more practicable it becomes. Conversely, when you stop using the trail, the vegetation grows back, and the trail slowly disappears. This is very similar to what happens in your brain-when you stop practicing something, the connections between your neurons weaken and can ultimately be dismantled or pruned. That is why it may seem so difficult to start reading again when school starts if you have not read all summer. However, it is possible for some neural networks to become so strong that the trails or connections never completely disappear.

The fact that learning rewires your neurons shows how dynamic (plastic) your brain is - that the brain changes and does not remain fixed. Practicing or rehearsing repeatedly activates your neurons and makes you learn. These changes happen as early as when a baby is in their mother's womb and continues throughout a person's life. So, the question is, how can you help your neurons to create and strengthen their connections? Here, we present two strategies that appear to be more compatible with how your brain works and could help you learn better.

\section{WHICH LEARNING STRATEGIES ARE MORE COMPATIBLE WITH YOUR BRAIN?}

\section{Strategy 1: Repeatedly Activating Your Neurons}

Because the connections between your neurons need to be activated multiple times to become stronger and more efficient, a first and crucial strategy is to repeatedly activate them. This means that to learn 
arithmetic tables for instance, you have to practice it repeatedly, to establish the "trail" between your neurons. As a baby, you were not able to speak and walk within 1 day: you practiced a lot. However, it is important to note that only reading or glancing at your arithmetic tables will not be that helpful in connecting your neurons. You might also find it quite disengaging and boring. To create the connections between your neurons, you need to retrieve the arithmetic tables from your memory. In other words, you have to try recall the answer yourself to activate your connections. We are not saying that this is easy to do! However, scientists think that this "struggle" improves learning because the challenge is an indication that you are building new connections. Remember, learning something new is like hiking in a bush with no designated trail, you will probably walk slowly at first, but if you keep hiking, trails will start forming and eventually you will be walking on well-beaten tracks. Besides, when you do try to recall what you have learned and make a mistake, it can help you identify gaps in your learning and give you an indication of which trail still needs to be worked on.

Scientists have also noted that performing tests or exams can help you remember information better than studying alone [4]. For example, if you study your arithmetic tables interspersed with test periods, you will probably perform better on your final test than if you had only studied. Why? The tests require that you retrieve the information from the neurons in which the information is stored, thus activating your connections and contributing to their strengthening. The point is thus to practice retrieval in an engaging way. There are different strategies that you could try at home, for example answering practice questions or using flashcards. These should improve learning more than re-reading or listening to lectures (as long as you do not flip the flashcard over before recalling the answer!). Other strategies include preparing questions to ask to a classmate or a parent as well as redoing tests or exercises. Use your imagination! What you need to remember is that first, for your neurons to strengthen their connections, you need to retrieve the information and avoid just reading or listening to the answer. Second, you should plan a way to get feedback to know whether you got something correct or incorrect. Do not be discouraged if you face challenges, this is a natural step of the learning process taking place in your brain!

Practicing more often but for a shorter period. For example, instead of studying for $2 \mathrm{~h}$ in a row, studying 4 periods of 30 min over a few days allows your brain to take breaks and sleep which helps you remember better in the long run.

\section{Strategy 2: Spacing the Activation of Neurons}

Now that you know that neurons need to be activated repeatedly for learning to occur (and that it means retrieving information), you probably wonder how often you should practice. Scientists who study the learning brain observed that breaks and sleep between learning periods enhance learning and minimize forgetting [5]. It therefore seems better to retrieve often within spaced practice sessions, as opposed to a massed practice (practicing a task continuously without rest). For instance, instead of studying or doing homework for $3 \mathrm{~h}$, 
after which you would probably feel exhausted anyway, you could separate this learning period into three 1 -h periods or even into six half-an-hour periods. In short, when spacing your retrieval practice, you allow your brain to make the connections that you strengthened during your practice sessions more efficient. When you take a quick break from practicing, let us say a 20 min recess, you allow for the maintenance or replacement of the receptors on the surface of the neurons. The receptors are like electric outlets that receive the nerve impulse (electrical signals) from other neurons. Taking a break helps them work better: your neurons can thus transmit their nerve impulses more easily to other neurons. Finally, when you get a night of sleep between practice sessions, you actually benefit from a free retrieval practice session because while you sleep, your brain reactivates the connections between the neurons that you activated during the day. You could also get similar benefits from a nap. Next time you find yourself sleepy in class, you could tell your teacher that you are in fact trying to do retrieval practice! In brief, when spacing out learning, and especially retrieval practice, your brain is more activated than when you mass learn in one long session.

At this point, you are probably asking yourself how to space out learning in your day-to-day life. The good news is that there are a number of ways to do it and it can be easily adapted to different skills, such as solving mathematical problems or memorizing definitions. The most obvious change you can make to your study schedule is to break up sessions into smaller sessions. You could also ask your teacher to set daily or weekly review quizzes and other assignments. Finally, spacing can be done by doing interleaved practice. This consists of a set of problems arranged so that consecutive problems cannot be solved by the same strategy. For example, you could mix your math problems so that geometry questions, algebra, or inequality problems are randomly sequenced. The added benefit of interleaving is that you engage in different activities in-between two sessions, making good use of your time. In brief, one thing to keep in mind is that information that was previously learned will require less effort to re-learn because the spacing gives your brain time to consolidate-meaning your brain produces the building blocks required for the connections between your neurons.

\section{CONCLUSION}

Your brain is where learning occurs and you therefore need to keep your neurons active to optimize the use of class or study time. The two learning strategies proposed in this article have the potential to help you learn better by creating optimal conditions to strengthen and consolidate the connections between your neurons. You now know that you can get better by repeatedly using the "trails" in your brain and by spacing out your practice. This greater understanding of how 
your brain learns and the use of supportive learning strategies can now allow you to help your brain learn better!

\section{ACKNOWLEDGMENTS}

We would like to wholeheartedly thank those who assisted in the translation of the articles in this Collection to make them more accessible to kids outside English-speaking countries, and for the Jacobs Foundation for providing the funds necessary to translate the articles. For this article, we would especially like to thank Nienke van Atteveldt and Sabine Peters for the Dutch translation.

\section{REFERENCES}

1. Blanchette Sarrasin, J., Nenciovici, L., Brault Foisy, L.-M., Allaire-Duquette, G., Riopel, M., and Masson, S. 2018. Effects of inducing a growth mindset in students by teaching the concept of neuroplasticity on motivation, achievement, and brain activity: a meta-analysis. Trends Neurosci. Educ. 12:22-31. doi: 10.1016/j.tine.2018.07.003

2. Rossi, S., Lanoë, C., Poirel, N., Pineau, A., Houdé, O., and Lubin, A. 2015. When i met my brain: participating in a neuroimaging study influences children's naive mind-brain conceptions. Trends Neurosci. Educ. 4:92-7. doi: 10.1016/j. tine.2015.07.001

3. Kania, B. F., Wronska, D., and Zieba, D. 2017. Introduction to neural plasticity mechanism. J. Behav. Brain Sci. 7:41-8. doi: 10.4236/jbbs.2017.72005

4. Zaromb, F. M., and Roediger, H. L. 2010. The testing effect in free recall is associated with enhanced organizational processes. Mem. Cogn. 38:995-1008 doi: 10.3758/MC.38.8.995

5. Callan, D. E., and Schweighofer, N. 2010. Neural correlates of the spacing effect in explicit verbal semantic encoding support the deficient-processing theory. Hum. Brain Mapp. 31:645-59. doi: 10.1002/hbm.20894

SUBMITTED: 30 September 2019; ACCEPTED: 26 March 2020; PUBLISHED ONLINE: 14 May 2020.

EDITED BY: Nienke Van Atteveldt, Vrije Universiteit Amsterdam, Netherlands

CITATION: Blanchette Sarrasin J, Brault Foisy L-M, Allaire-Duquette G and Masson S (2020) Understanding Your Brain to Help You Learn Better. Front. Young Minds 8:54. doi: 10.3389/frym.2020.00054

CONFLICT OF INTEREST: The authors declare that the research was conducted in the absence of any commercial or financial relationships that could be construed as a potential conflict of interest.

COPYRIGHT (c) 2020 Blanchette Sarrasin, Brault Foisy, Allaire-Duquette and Masson. This is an open-access article distributed under the terms of the Creative Commons Attribution License (CC BY). The use, distribution or reproduction in other forums 

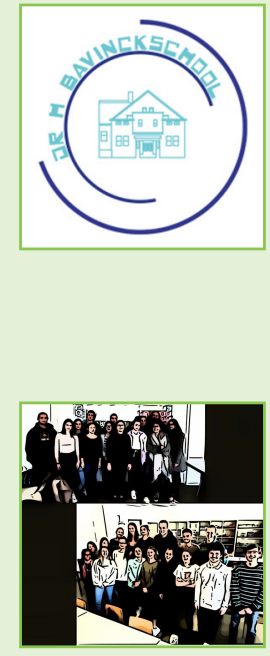

\section{YOUNG REVIEWERS}

DR. H. BAVINCKSCHOOL, AGES: 8-12

We are Spectrum classes 5-6 and 7-8 of the Bavinckschool in Haarlem, the Netherlands. This is a group of 40 kids (19 in group 5-6 and 21 in group 7-8) who are eager to learn a bit more than the regular school program. They had a lot of fun reviewing for FYM, and went through the articles with great focus and enthusiasm, and made a critical evaluation. They really enjoyed contributing to science and helping out!

\section{LOCARNO HIGH SCHOOL, AGES: 17-18}

HI! We are two classes of Locarno High School in Switzerland. We study chemistry and biology. We are in the last year of high school, and we are preparing for our final exams, which will begin in 2 months. It was a great experience analyzing the article, and we thank you for the activity you have given us. Thanks to you, we were able to give feedback on a scientific text in English (which is not our mother tongue). We really felt empowered!

\section{AUTHORS}
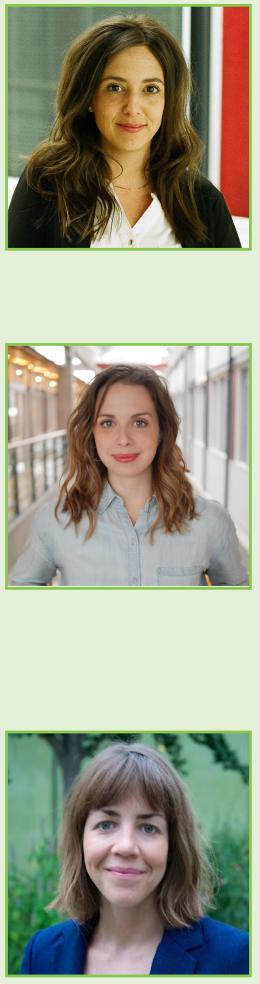

\section{JÉRÉMIE BLANCHETTE SARRASIN}

I am a Ph.D. student at Université du Québec à Montréal. I study how the brain learns and how it is possible to benefit from this knowledge to foster teaching practices that are more compatible with the learning brain. My research actually focuses on teaching students how their brain learns to help them learn better! *blanchette_sarrasin.jeremie@uqam.ca

\section{LORIE-MARLÈNE BRAULT FOISY}

I am a professor at the University of Quebec in Montreal (UQAM). After studying to become a teacher in elementary school, I decided that I wanted to know more about how children learn. This is why I am doing research in education. I believe that it is important to understand better what happens in the brain of children when they learn different things (e.g., reading, science). If we understand better how their brain learn, it will give us clues to teach better!

\section{GENEVIÈVE ALLAIRE-DUQUETTE}

I am a post-doctoral fellow at the Constantiner School of Education, Tel Aviv University. My research and teaching focus on the interdisciplinary study of human learning, development, and teaching, namely Mind, Brain, and Education (MBE). My current work attempts to better understand the mechanisms of reasoning in science and mathematics using cognitive neuroscience methods. 


\section{STEVE MASSON}

I am a professor at Université du Québec à Montréal. Using a tool called magnetic resonance imaging, I look inside the brain to see what changes when students learn in school. Sometimes, I even look if the way teachers teach influences what change in students' brain when they learn. Pretty cool! 